\title{
BMJ Open Cohort profile: the SHoT-study, a national health and well-being survey of Norwegian university students
}

\author{
Børge Sivertsen, ${ }^{1,2,3}$ Hege Råkil, ${ }^{4}$ Espen Munkvik, ${ }^{5}$ Kari Jussie Lønning ${ }^{6,7}$
}

To cite: Sivertsen B, Råkil H, Munkvik E, et al. Cohort profile: the SHoT-study, a national health and wellbeing survey of Norwegian university students. BMJ Open 2019;9:e025200. doi:10.1136/ bmjopen-2018-025200

- Prepublication history for this paper is available online. To view these files, please visit the journal online (http://dx.doi. org/10.1136/bmjopen-2018025200).

Received 3 July 2018 Revised 3 November 2018 Accepted 5 November 2018

Check for updates

(c) Author(s) (or their employer(s)) 2019. Re-use permitted under CC BY-NC. No commercial re-use. See rights and permissions. Published by BMJ.

${ }^{1}$ Department of Health Promotion, Norwegian Institute of Public Health, Bergen, Norway ${ }^{2}$ Department of Research and Innovation, Helse Fonna HF, Haugesund, Norway ${ }^{3}$ Department of Mental Health, Norwegian University of Science and Technology, Trondheim,

Norway

${ }^{4}$ The Student Welfare

Association of Western Norway (Sammen), Bergen, Norway

${ }^{5}$ The Student Welfare

Association of Trondheim (SiT), Trondheim, Norway

${ }^{6}$ Vestre Viken HF, Drammen,

Norway

${ }^{7}$ The Student Welfare

Association of Oslo and

Akershus (SiO), 0slo, Norway

Correspondence to

Professor Børge Sivertsen;

borge.sivertsen@fhi.no

\section{ABSTRACT}

Purpose The SHoT study was set up as a national student health survey for higher education in Norway, conducted at 4-year intervals. The dataset comprises a wide range of self-reported data covering information on mental and physical health, quality of life, health-related behaviours as well as more specific study-related information.

Participants The SHoT studies conducted so far in 2010 , 2014 and 2018, included 6053, 13525 and 50054 fulltime students (aged 18-35), respectively.

Findings to date The main results from the first two waves have been published in three comprehensive Norwegian reports, with the most important finding being an increase in mental health problems (HSCL-score $\geq 2.0$ ) among Norwegian college students from 2010 (16\%) to 2014 (21\%) to 2018 (29\%).

Future plans The next SHoT study will be conducted in 2022, 2026 and so on. Starting from 2018-study, the survey data can also be linked to several national registers.

\section{INTRODUCTION}

Epidemiological studies suggest that $12 \%-50 \%$ of college students meet criteria for one or more common mental disorders, ${ }^{1-3}$ and mental disorders in this age group are associated with long-term adverse outcomes, including persistent emotional and physical health problems ${ }^{4}$ and labour market marginalisation. ${ }^{5}{ }^{6}$ Mental health problems are also directly associated with lower academic performance, which in turn, is associated with dropout in the shortterm and loss of human capital for societies in the longer term. ${ }^{7}$ As such, mental health problems in college students constitute both a clinical, educational problem and societal problem.

Still, there are few large epidemiological studies on the prevalence of mental health problems in college students, despite being a crucial transitional period making in particularly important to study. First, most mental disorders have an onset in late adolescence and early adulthood. ${ }^{8}$ Second, the proportion of young adults now attending higher
Strengths and limitations of this study

The SHoT study is a national student health survey for higher education in Norway, conducted at 4-year intervals.

- The SHoT studies conducted so far in 2010, 2014 and 2018, included 6053, 13525 and 50054 fulltime students (aged 18-35), respectively.

- The dataset comprises a wide range of self-reported data covering information on mental and physical health, quality of life, health-related behaviours as well as more specific study-related information.

- The SHoT2018, and future waves, allow the data to be linked to several national registers.

- A limitation is the relatively low response rate for both the SHoT2010 (23\%), SHoT2O14 (29\%) and SHoT2018 (31\%).

education has increased steadily in recent decades. In 2015, close to half of the Norwegian adult population (aged 25-64 years) had completed higher education, and the number is growing. ${ }^{9}$ In a Canadian study, less than $40 \%$ of $18-24$ year olds who were depressed had spoken to a health profession about their mental health in the last 12 months. ${ }^{10}$ As such, detecting mental health problems among college students provides excellent opportunities for addressing the substantial burden of early-onset mental problems. In addition, identifying this population at an early stage in their adult life has several important benefits, given the substantial consequences that mental health problems have on subsequent educational, social and economic outcomes.

The SHoT study (an acronym for the Norwegian name: Studentenes Helse- og Trivselsundersøkelse [Students' Health and Wellbeing Study]) is a national student survey for higher education in Norway. So far, three health surveys of the student population in Norway have been completed (2010, 2014 and 2018). Both the size and scope of the SHoT studies have expanded over time, and now includes detailed information on mental and physical health, quality of life, health-related behaviours, demographics 
Table 1 Overview of the main included instruments/variables in the SHoT studies

\begin{tabular}{llcc}
\hline Domain & Instruments and description & 2010 & $\mathbf{2 0 1 4}$ \\
\hline $\begin{array}{l}\text { Mental health } \\
\text { and well-being }\end{array}$ & $\begin{array}{l}\text { Psychological distress was assessed using The Hopkins Symptoms Checklist (HSCL-25), }{ }^{14} \\
\text { derived from the 90-item Symptom Checklist (SCL-90), which is a screening tool designed to } \\
\text { detect symptoms of anxiety and depression. It is composed of a 10-item subscale for anxiety and }\end{array}$ & x \\
& $\begin{array}{l}\text { a 15-item subscale for depression, with each item scored on a Likert scale from 1 (not at all) to } 4 \\
\text { (extremely). The period of reference is the past 2 weeks. }\end{array}$
\end{tabular}

Perfectionism was assessed by the short version of the Perfectionism subscale from the Eating Disorder Inventory (EDI). ${ }^{22}$

\section{In SHoT2018 loneliness was assess using an abbreviated version of the widely used UCLA} Loneliness Scale, 'The Three-Item Loneliness Scale (T-ILS)'. ${ }^{23}$ The Three-Item Loneliness Scale has displayed satisfactory reliability and both concurrent and discriminant validity.

In ShoT2010 and 2014, social and emotional loneliness were assessed using the Social and Emotional Loneliness Scale, ${ }^{24}$ which is an extension of the tool originally developed by Russell et al. ${ }^{25}$ The scale consists of two five-item measures which assess concepts of social and emotional loneliness. Previous psychometric assessments of the coefficient alphas for both constructs of the scale have yielded acceptable values $(0.78$ and 0.76 for emotional and social loneliness, respectively). When compared with other measures of loneliness (such as the UCLA loneliness scale), ${ }^{26}$ evaluations of convergent validity for the Wittenberg ${ }^{24}$ scale yielded acceptable correlation coefficients of 0.81 for social loneliness and 0.59 for emotional loneliness. ${ }^{27}$

Eating disturbances was assessed by the Eating Disturbance Scale (EDS-5), ${ }^{28}$ a brief screening instrument for problematic eating in normal populations. The EDS- 5 has been shown to have good concurrent and construct validity with respect to DSM-IV eating disorders.

Quality of life was assessed by the Satisfaction With Life Scale (SWLS). ${ }^{29}$ The SWLS is a five-item $x$ scale designed to measure global cognitive judgments of one's life satisfaction (not a measure of either positive or negative affect). Participants indicate how much they agree or disagree with each of the five items using a 7-point scale that ranges from 7 (strongly agree) to 1 (strongly disagree).

\section{Positive affect (PA) was assessed by the PA subscale of the Positive and Negative Affect}

Schedule (PANAS). ${ }^{30}$ The PA scale includes the terms 'interested', 'alert', 'enthusiastic', 'excited', 'proud', 'inspired', 'strong', 'active' and 'attentive'. Participants are instructed to rate the extent to which they usually experience each emotion, rated on a 5-point scale from 'very slightly or not at all' to 'extremely'.

History of suicidal ideation, suicide attempts and self-harm were assessed with three items drawn from the Adult Psychiatric Morbidity Survey (APMS); ${ }^{31}$ while questions about self-harm thoughts was adapted from the Child and Adolescent Self-harm in Europe study (CASE). ${ }^{32}$ If respondents answered yes to any item, timing of the

most recent episode, frequency of episodes and age at first onset were then assessed.

Sleep variables: Typical bedtime, rise time, sleep onset latency (SOL) and wake after sleep onset (WAS) were reported separately for weekends and weekdays. The participants also indicated the number of nights per week they experienced difficulties initiating sleep, difficulties maintaining sleep, early morning awakenings, snoring, breathing cessations during sleep as well as daytime sleepiness and tiredness. Participants were also asked for how long they had suffered from these sleep problems. This information was used as an operationalisation for insomnia disorder, according to the DSM-5 criteria. $^{33}$

Bullying was assessed with the Olweus Bully/Victim Questionnaire ${ }^{34}$ arguably the most widely used bullying self-report survey in the world. ${ }^{35}$ Studies using the BVQ have been conducted in at least 15 countries.

Sexual harassment is commonly defined as unwanted and unwelcome sexual behaviour in a work or educational setting affecting both physical and psychological well-being of a person. It could be evident in three different ways: verbal, physical and non-verbal forms. ${ }^{36}$ In the current study, sexual harassment was assessed using seven items covering these three forms, also corresponding to the legal definition of Norwegian regulations:

1. Verbal harassment (sexual expressions and suggestions, comments about body, appearance or private life).

2. Non-verbal harassment (2a: close eye or body movements, $2 \mathrm{~b}$ : viewing sexual images (including digital), $2 \mathrm{c}$ : blotting and the like).

3. Physical harassment (3a: unwanted touching, hugging or kissing, 3b: rape attempt and 3c: rape).

For each of the seven types of harassment, the respondents also indicated who committed the harassment act (fellow student, employed at the educational institution or others), when the harassment was experienced (last month, last year, more than a year ago, but after I started studying and before I started studying) and how many times he/she had experienced to be sexually harassed. 


\begin{tabular}{|c|c|c|c|c|}
\hline Domain & Instruments and description & 2010 & 2014 & 2018 \\
\hline Somatic health & $\begin{array}{l}\text { Somatic health was assessed by the Somatic Symptom Scale- } 8 \text { (SSS-8): }{ }^{37} \text { an } 8 \text {-item reliable and } \\
\text { valid self-report measure of somatic symptom burden. Cut-off scores identify individuals with low, } \\
\text { medium, high and very high somatic symptom burden. }\end{array}$ & & & $x$ \\
\hline
\end{tabular}

Physical and mental conditions were assessed by a predefined list adapted to fit this age cohort.
The list is based on a similar operationalisation used in previous large population based studies
(the HUNT study) and included several subcategories (not listed here) for most conditions: allergy
and intolerances, asthma, cerebral palsy, diabetes, eczema, epilepsy, heart disease, hearing
impairments, irritable bowel, cancer, reading and writing difficulties migraine, mental disorders,
visual disabilities

Health Alcohol consumption: Participants assessed with the Alcohol Use Disorder Identification Test

behaviours (AUDIT). ${ }^{38}$ The AUDIT consists of 10 items from three domains: consumption patterns (questions one to three), dependence symptoms (questions four to six) and harmful consequences of drinking (questions 7 to 10). Each item has response options that can be scored from 0 to 4 . The scores from the 10 items are summarised, yielding a total score ranging from 0 to 40 . A total score of 8 (or more) for men and 6 (or more) for women are used to indicate risky drinking and above 13 and 11, respectively, to indicate hazardous drinking.

\begin{tabular}{|c|c|c|c|c|}
\hline & $\begin{array}{l}\text { Physical activity in } 2018 \text { was assessed using three sets of questions, assessing the average } \\
\text { number of times exercising each week and the average intensity and average hours each time: } \\
\text { 'How frequently do you exercise?' (Never, Less than once a week, Once a week, 2-3 times per } \\
\text { week, Almost every day). } \\
\text { 'If you do such exercise as frequently as once or more times a week: How hard do you push } \\
\text { yourself? (I take it easy without breaking into a sweat or losing my breath, I push myself so } \\
\text { hard that I lose my breath and break into a sweat, I push myself to near-exhaustion). } \\
\text { 'How long does each session last?' (Less than } 15 \text { min, 15-29 min, } 30 \text { min to } 1 \text { hour, More than } \\
1 \text { hour'. } \\
\text { Respondents were also asked if they considered themselves to be a 'top athlete', and if so, in } \\
\text { what sport, and how many hours per week they trained. } \\
\text { Physical activity in } 2010 \text { and } 2014 \text { was also measures, but not as detailed as in the SHoT2018 } \\
\text { study. }\end{array}$ & (x) & $(x)$ & $x$ \\
\hline & $\begin{array}{l}\text { Illegal drug use was assessed by asking if the participants had used either of the following } \\
\text { substances during the last } 12 \text { months: amphetamine or methamphetamine, benzodiazepines } \\
\text { without prescription (Sobril, Valium and so on) cannabis (hashish/marijuana), ecstasy, GHB, } \\
\text { heroin, cocaine, LSD, psilocybin, MDMA, Ritalin without prescription, synthetic cannabinoids } \\
\text { (spice) and other drugs. The response options were: Never, } 1 \text { time, 2-4 times, } 5-50 \text { times. More } \\
\text { than } 50 \text { times. }\end{array}$ & & & $x$ \\
\hline $\begin{array}{l}\text { Other } \\
\text { information }\end{array}$ & $\begin{array}{l}\text { A range of other demographical and background factors were also assessed, including age, } \\
\text { gender (male, female, transperson), annual income, economic difficulties, sexual orientation (and } \\
\text { problems related to this), relationship status, birth country/ethnicity (self and parents and cultural } \\
\text { discrimination based on this), annual, study satisfaction, voluntary work and so on. }\end{array}$ & $(x)$ & $(x)$ & $x$ \\
\hline
\end{tabular}

and more specific study-related information. The background for the first survey was that there existed limited data on these topics in the student population. Although some data had been collected locally at campuses from small surveys before 2010, no systematic surveys had been conducted yielding more comprehensive knowledge. On this backdrop, the three largest student associations in Norway assembled to set up a national survey to be repeated every 4 years, with the ambition to build a representative knowledge base on student health.

The main scientific aim of the SHoT study is twofold: (1) to examine prevalence and trends across a range of health problems and life challenges among college and university students and (2) to examine both predictive factors all the way from birth through adolescence as well as to investigate important outcomes in terms of subsequent health, educational success and work situation, by linking the SHoT2018 survey to several high quality national registries.

\section{COHORT DESCRIPTION}

\section{Setting}

Norway is a Northern European country characterised as a social democratic welfare state, with generous universal public health insurance coverage, and predominately public health services. Higher education in Norway is offered by 8 universities, 9 specialised universities, 24 university colleges and several private university colleges. Public education is free, with an academic year with two semesters, from August to December and from January to June. All students belong to a student welfare association that takes care of such services as housing, kindergartens, advisory services and some healthcare. 


\section{The SHoT2010 study}

The SHoT2010 was conducted by TNS Gallup on behalf of the student societies in Oslo, Bergen and Trondheim, and with additional participation from Stavanger, Oppland, Telemark and Finnmark. The data collection internet-based and was conducted during the period 11 October to 8 November 2010. The target group was Norwegian full-time students $<35$ years of age. A total of 6053 students completed the survey, yielding a response rate of $23 \%$. At the time, this was the most comprehensive survey conducted on students' health and well-being in Norway.

\section{The SHoT2014 study}

The SHoT2014 study was a collaboration between the 10 largest student welfare associations in Norway (Oslo, Bergen and Trondheim), targeting full-time Norwegian students $<35$ years of age. Data for the SHoT study were collected using an internet platform in the period from 24 February 2014 to 27 March 2014. An invitation email containing a link to an anonymous online questionnaire was sent to 47514 randomly selected students and stratified by study institutions, faculties and departments. The overall response rate was $28.5 \%$ and included all 13525 students with valid response on the sleep questionnaire. Written informed consent was obtained from all participants prior to data collection. Approval for conducting the SHoT study was granted by the Data Protection Officer for research at the Norwegian Social Science Data Services, as ombudsman for Inspectorate.

\section{The SHoT2018 study}

The SHoT2018 study was a joint effort between the Norwegian Institute of Public Health (NIPH) and all student welfare associations in Norway. The study was conducted between 6 February and 5 April 2018 on all fulltime Norwegian students taking higher education (both in Norway and abroad). The collection of the health survey was in close collaboration with all the student welfare associations in the Norway, and several institutions allocated

\section{Table 2 Overview of other data sources/registers scheduled to be linked to the SHoT2018}

The Medical Birth Registry of MBRN is a national health registry containing information about all births in Norway. The registry Norway (MBRN)

has been widely used to identify causes and consequences of health problems related to pregnancy and birth as well as to monitor the incidence of congenital abnormalities. The MBRN also includes information about maternal health before and during pregnancy, in addition to data on the parents' occupation and smoking habits.

The KUHR (control and payment of reimbursements to health service providers)

The Norwegian Prescription Database (NorPD) The Norwegian Patient
Registry (NPR)

The National Educational Database (NUDB)

\section{The Norwegian Cause of} Death Registry

The National Conscript Service

Norwegian Social Insurance Database

The KUHR database is owned by the Norwegian Directorate of Health and includes data on reimbursement to GPs for the healthcare service they provided to primary healthcare service users. The report sent by each GP contains detailed information about the diagnosis and treatment.

The NorPD was established on 1 January 2004 at the Norwegian Institute of Public Health. The NorPD monitors drugs dispensed by prescription in Norway and contains data on all prescriptions, including type of medication (ATC-code) and dosage. All pharmacies in Norway register prescriptions electronically and the information is sent in monthly reports to NorPD.

The NPR is a comprehensive registry of inpatient and outpatient hospital care in Norway. The registry is owned and funded by the Norwegian Directorate of Health and is run by SINTEF Health Research. The registry contains detailed data on each individual's history of diagnose(s) and treatments from the high school years throughout his/her college/university education.

The NUDB includes information about completed education at all levels, grades and school dropout. The database includes individually based statistics on education since 1970, providing us with relevant information for all the included age cohorts.

The Norwegian Cause of Death Registry is kept by NIPH and includes information on cause of death for all deceased persons registered as residents in Norway at the time of death.

Norwegian Armed Forces provides register data from the National Conscript Service, which includes high quality intelligence test scores, physical and mental health, lifestyle factors.

As payment of social insurance benefits is a governmental responsibility in Norway, all payments are accurately recorded in the Norwegian Social Insurance Database, Forløpsdatabasen Trygd (FD-Trygd). The registry is complete for the Norwegian population and is continuously updated. The data in the registries include type of benefit, degree of compensation, start and end date of benefit recipiency and medicolegal diagnosis. The data sources for FD-Trygd are administrative registries from Statistics Norway, NAV and the former State Public Employment Service.

The youth@hordaland study The youth@hordaland survey was a large population-based study of adolescent mental health problems. All adolescents attending secondary education (aged 16-19years.) in Hordaland County during spring 2012 were invited to participate. The main aim of the survey was to assess the prevalence of mental health and substance use problems in adolescence. Of the 19430 invited to take part, 10200 agreed yielding a participation rate of 53\%. 
Table 3 Brief overview of some key findings from the SHoT2010 and SHoT2014

$\begin{array}{lll}\text { SHoT2010 SHoT2014 SHoT2018 } & \text { SH }\end{array}$

Health problems

$16 \%$ of students report severe mental problems (HSCL-25 $\geq 2.0)$. The prevalence of mental problems is higher among women than men.

\section{$21 \%$ of students report severe mental}

symptoms. The prevalence is twice as high among students as in the normal population of the same age group and twice as high among women compared with men. The increase since 2010 is stronger in women. $24 \%$ of female students now report severe mental symptoms, compared with $12 \%$ among men.

About $1 / 3$ of those with serious mental problems have sought help in the past year.

7 out of 10 students say they have good or very good physical health. About $5 \%$ report their physical health as bad.

\section{Every 20 students report social loneliness} while $12 \%$ is emotionally lonely. The extent of social loneliness is greater among men than women.

Every 10th student has significant examination anxiety, and $15 \%$ have significant fear of oral presentations or to speak in academic contexts. Both are twice as common in women compared with men.

The proportion of low school-related selfefficacy is $13 \%$. Every 5 th student has high self-efficacy. Low study-related self-efficacy is clearly more common among women.

The majority of students report their own quality of life as good, while $13 \%$ of students report poor quality of life.

\section{Lifestyle behaviours}

$16 \%$ of the students report drinking alcohol several times per week.

$17 \%$ of students have a drinking pattern that involves serious risk. $43 \%$ have high or severe risk behaviours associated with alcohol.

\section{As in 2010 , only $1 / 3$ of those with serious} mental problems have sought help last year.

7 out of 10 students say they have good or very good physical health. $7 \%$ perceive their physical health as bad.

As in $2010,5 \%$ of the students report socia loneliness while $12 \%$ are emotionally lonely. Men are lonelier than women, both socially and emotionally.

As in 2010, examination anxiety and fear of oral presentations are twice as common in women compared with women.

The proportion of low school-related selfefficacy is $13 \%$, while every 5 th student have high self-efficacy. Low self-efficacy is more common among women than men.

The majority of students report their quality of life as good or medium good. $14 \%$ of students report poor quality of life. No gender differences.

$14 \%$ of the students drink alcohol several times per week. There is a declining trend of 2010 among both sexes. Men still drink more often than women.

$3 \%$ of students have a drinking pattern that involves serious risk. $40 \%$ have high or severe risk behaviours associated with alcohol. Men are overrepresented in both groups.
$29 \%$ of students score above the 2.0 cutoff on the HSCL-25. The increase since 2010 is stronger in women. $34 \%$ of female students now report severe mental symptoms, compared with $17 \%$ among men.

\section{$\mathrm{n} / \mathrm{a}$}

8 out of 10 students say they have good or very good physical health. Only $2 \%$ perceive their physical health as bad.

Around $10 \%$ report feeling lonely, and the prevalence is higher among women.

In $2018,14 \%$ of the students have significant examination anxiety (women 16\%, men $8 \%$ ).

$\mathrm{n} / \mathrm{a}$

The majority of students report their quality of life as good or medium good. $15 \%$ of students report poor quality of life. No gender differences.

As in $2014,14 \%$ of the students drink alcoho several times per week. Men still drink more often than women.

$5 \%$ of students have a drinking pattern that involves serious risk. $38 \%$ have high or severe risk behaviours associated with alcohol. Men are overrepresented in both groups.

School-related variables

The satisfaction with the study towns is overall high, and few are dissatisfied. The majority of the students report having been well received at the study programme.

There is a clear positive association between participation in the student introductory week and reports of being well received on the study programme.

Work pressure and concentration difficulties are often experienced as a problem in almost every 5 students, while many experience this occasionally.
There is a high and increasing satisfaction with There is a high and stable satisfaction with the study towns in general. Most students feel the study towns in general. Most students feel well received on the study programmes. well received on the study programmes.
$45 \mathrm{~min}$ in student classes allowing for sufficient time for the students to complete the set of questionnaires. The survey data were collected electronically through a web-based platform. In all 162512 students fulfilled the inclusion criteria, of whom 50054 students completed the online questionnaires, yielding a response rate of $31 \%$.
Representativeness of the SHoT2018

Compared with all invited students $(58.1 \%$ women $(n=93267)$ and $41.9 \%$ men $(n=67558))$, the SHoT2018 sample included a larger proportion of women $(69.1 \%)$ than men $(30.9 \%)$. The mean age was 23.2 years $(\mathrm{SD}=3.3)$, and the age distribution of participating students (18-20 
years $(18 \%, \mathrm{n}=8832), 21-22$ years $(31 \%, \mathrm{n}=15471), 23-25$ years $(32 \%, \mathrm{n}=15902), 26-28$ years $(12 \%, \mathrm{n}=5710)$ and $29-35$ years $(7 \%, \mathrm{n}=3427))$, was almost identical to that of all invited students (18-20 years $(18 \%, \mathrm{n}=28996), 21-22$ years $(31 \%, \mathrm{n}=49731), 23-25$ years $(32 \%, \mathrm{n}=51714), 26-28$ years $(12 \%, \mathrm{n}=19901)$ and $29-35$ years $(7 \%, \mathrm{n}=10216))$. As response rates are particularly important in prevalence studies, care should be taken when generalising the current findings to the whole student population. Rather, it may be more appropriate to explore associations/correlations and to emphasise the relative differences between men and women as well as different age cohorts, as these estimates are less prone to selection bias.

\section{Instruments}

An overview of the main included instruments/variables in the three SHoT studies is presented in table 1 , covering self-reported information on both mental and physical health, quality of life, health-related behaviours as well as more specific study-related information. While some instruments (eg, HSCL-25, AUDIT and SWLS) were used for all three SHoT-studies, other instruments and questionnaire were specific for each study. Especially the SHoT2018 study included several new instruments, which the student welfare associations, were very interested in including in the new survey. Of particular interest were instruments assessing sexual harassment, bullying and self-harm/suicidal ideation, which so far have received little attention in student populations.

\section{Linkage to registers covering all participants}

The first two studies (SHoT2010 and SHoT2014) were anonymous, but the SHoT2018 also collected the participants' unique Norwegian 11-digit personal identification number. This allows data from SHoT participants to be linked to several national health registers, of which the most important data sources are displayed in table 2. In terms of planned scientific use, linkages to these registries will allow us to examine a range of novel research questions, for example: The Medical Birth Registry of Norway (MBRN) may be used to identify causes of health problems and medical conditions related to pregnancy and birth, which again may linked to academic performance for specific subgroups during the college years. Furthermore, linking the SHoT2018 study to the KUHR database will, for example, allow us to examine predictive factors in SHoT2018 in relation to later primary healthcare use, and similarly, the Norwegian Patient Registry (NPR) will allow us to explore predictors and outcomes using data from the specialist care (data on diagnosis and treatment). Another scientific aim will be to link SHoT2018 to the National Educational Database (NUDB), which includes information about completed education at all levels, grades and school-drop out. This will enable us to examine potential risk and protective factors for both academic success and dropout from college/university. Finally, data from the Norwegian Social Insurance Database (FD-Trygd) will allow us to investigate the students' later work life participation, including both risk and protective factors. As such, the additional scientific benefits, only briefly outlined here, by linking the SHoT2018 to national registers, are substantial.

\section{PATIENT AND PUBLIC INVOLVEMENT}

The planning and design of the study were initiated and governed by the student welfare associations, which included deciding inclusion and exclusion criteria, and selecting potential research questions and instruments. Students were not involved in the actual collection of data, although recruitment was conducted in close collaboration with all the student welfare associations in Norway. The results will be disseminated to the study participants via outlets of the student welfare associations and educational institutions, with newsletters highlighting main findings being made available to all students. Popular summaries of results and interpretations with interest for a wider audience will be disseminated in appropriate outlets (eg, the web pages of educational institutions and the NIPH).

\section{FINDINGS TO DATE}

Descriptive results from the SHoT2010, ${ }^{11}$ SHoT2014 ${ }^{12}$ and SHoT2018 ${ }^{13}$ have been published in three comprehensive Norwegian reports. Table 3 provides a brief overview of some of the main findings from these studies. In addition, some key findings from the SHoT2014 have been published in peer-reviewed international journals: Examining the psychometric properties of the included measure of mental health problems, the Hopkins Symptoms Check List (HSCL-25), ${ }^{14}$ Skogen et al concluded that a unidimensional model was most appropriate for HSCL-25 in student populations. ${ }^{15}$ Investigating sleep problems in college students, Hayley et al found that difficulties initiating or maintaining sleep was linked to increased risk of both social and emotional loneliness, ${ }^{16}$ as well as poorer academic outcomes and poorer self-rated academic proficiency. ${ }^{17}$ And focusing on the introductory week offered by most Norwegian higher education institutions, Myrtveit et al found that 7 of 10 students were satisfied with the introductory week, and that participation in the event was associated with better social integration, although some felt excluded due to the amount of alcohol involved. ${ }^{18} 19$

\section{STRENGTHS AND LIMITATIONS}

An obvious strength is the large sample size, especially for the SHoT2018, which allows studies of low frequent conditions/variables. A notable weakness is the relatively modest response rate for both the SHoT2010 (23\%), SHoT2014 (29\%) and SHoT2018 (31\%). It is possible that the use of a single, email-based survey approach contributed to this low response-rate, as web-based platforms typically yield lower overall participation rates 
when compared with traditional mail approaches, such as mail survey or face-to face interviews. ${ }^{20}$ The potential bias introduced by selective recruitment to the cohort is an obvious limitation regarding prevalence measures, but appears to have minimal influence on exposure-disease associations. $^{21}$

\section{COLLABORATION}

The SHoT dataset is administrated by the NIPH. Approval from a Norwegian regional committee for medical and health research ethics (https://helseforskning.etikkom. no) is a pre-requirement. Guidelines for access to SHoT data are found at https://www.fhi.no/en/more/ access-to-data.

Acknowledgements We wish to thank all participating students as well as the three largest student associations in Norway (SiO, Sammen and SiT), who initiated and designed SHOT studies.

Contributors BS drafted the manuscript, with contributions from HR, EM and KJL. HR, EM and KJL designed and established the SHoT study (for the SHoT2018 also $\mathrm{BS}$ ), and they are also responsible for the continued management of future waves. $H R, E M$ and KJL obtained funding, and BS was responsible for data management. All authors reviewed, critically revised and approved the manuscript.

Funding SHoT 2018 has received funding from the Norwegian Ministry of Education and Research (2017) and the Norwegian Ministry of Health and Care Services (2016).

Competing interests None declared.

Patient consent for publication Obtained.

Ethics approval The SHoT 2018 study was approved by the Regional Committee for Medical and Health Research Ethics in Western Norway (no. 2017/1176), and electronic informed consent was obtained after complete description of the study to the participants. Approvals for conducting the SHoT2010 and SHoT2014 studies were granted by the Data Protection Officer for research at the Norwegian Centre for Research Data.

Provenance and peer review Not commissioned; externally peer reviewed.

Data sharing statement Researchers interested in collaboration are invited to propose research projects. The SHoT dataset is administrated by the NIPH. Approval from a Norwegian regional committee for medical and health research ethics (https://helseforskning.etikkom.no) is a pre-requirement. Guidelines for access to SHoT data are found at https://www.fhi.no/en/more/access-to-data.

Open access This is an open access article distributed in accordance with the Creative Commons Attribution Non Commercial (CC BY-NC 4.0) license, which permits others to distribute, remix, adapt, build upon this work non-commercially, and license their derivative works on different terms, provided the original work is properly cited, appropriate credit is given, any changes made indicated, and the use is non-commercial. See: http://creativecommons.org/licenses/by-nc/4.0/.

\section{REFERENCES}

1. Verger P, Guagliardo V, Gilbert F, et al. Psychiatric disorders in students in six French universities: 12-month prevalence, comorbidity, impairment and help-seeking. Soc Psychiatry Psychiatr Epidemiol 2010;45:189-99.

2. Hunt J, Eisenberg D. Mental health problems and help-seeking behavior among college students. J Adolesc Health 2010;46:3-10.

3. Blanco C, Okuda M, Wright C, et al. Mental health of college students and their non-college-attending peers: results from the National Epidemiologic Study on Alcohol and Related Conditions. Arch Gen Psychiatry 2008;65:1429-37.

4. Scott KM, Lim C, Al-Hamzawi A, et al. Association of mental disorders with subsequent chronic physical conditions: world mental health surveys from 17 countries. JAMA Psychiatry 2016;73:150-8.

5. Goldman-Mellor SJ, Caspi A, Harrington $\mathrm{H}$, et al. Suicide attempt in young people: a signal for long-term health care and social needs. JAMA Psychiatry 2014;71:119-27.
6. Niederkrotenthaler T, Tinghog P, Alexanderson K, et al. Future risk of labour market marginalization in young suicide attempters-a population-based prospective cohort study. Int J Epidemiol 2014;43:1520-30.

7. Freudenberg N, Ruglis J. Reframing school dropout as a public health issue. Prev Chronic Dis 2007;4:1-11.

8. Kessler RC, Berglund P, Demler O, et al. Lifetime prevalence and age-of-onset distributions of DSM-IV disorders in the National Comorbidity Survey Replication. Arch Gen Psychiatry 2005;62:593-602.

9. OECD. Education at a Glance 2015: OECD Indicators. Paris: OECD Publishing, 2015

10. MacKinnon N, Colman I. Factors Associated with Suicidal Thought and Help-Seeking Behaviour in Transition-Aged Youth versus Adults. Can J Psychiatry 2016;61:789-96.

11. Nedregård T, Olsen R. Studentenes helse- og trivselsundersøkelse 2010]. 2011 http://lykkepromille.no/wp-content/uploads/2016/04/ SHoT-2010_Rapport.pdf

12. Nedregård T. [Studentenes helse- og trivselsundersøkelse 2014]. 2014 http://www.studentvelferd.no/dokumenter/2014/09/SHoT2014_Rapport_.pdf

13. Knapstad M, Heradstveit O, Sivertsen B. [Studentenes helse- og trivselsundersøkelse 2018]. 2011 https://shotstorage.blob.core. windows.net/shotcontainer/SHOT2018.pdf

14. Derogatis LR, Lipman RS, Rickels K, et al. The Hopkins Symptom Checklist (HSCL): a self-report symptom inventory. Behav Sci 1974;19:1-15.

15. Skogen JC, Øverland S, Smith ORF, et al. The factor structure of the Hopkins Symptoms Checklist (HSCL-25) in a student population: a cautionary tale. Scand J Public Health 2017:45:357-65.

16. Hayley AC, Downey LA, Stough C, et al. Social and emotional loneliness and self-reported difficulty initiating and maintaining sleep (DIMS) in a sample of Norwegian university students. Scand $J$ Psychol 2017;58:91-9.

17. Hayley AC, Sivertsen B, Hysing M, et al. Sleep difficulties and academic performance in Norwegian higher education students. $\mathrm{Br} \mathrm{J}$ Educ Psychol 2017;87:722-37.

18. Myrtveit SM, Askeland KG, Knapstad M, et al. The Norwegian student introductory week: who takes part, and is participation associated with better social integration and satisfaction among students? European Journal of Higher Education 2017;7:136-52.

19. Myrtveit SM, Askeland KG, Knudsen AK, et al. Risky drinking among Norwegian students: Associations with participation in the introductory week, academic performance and alcohol-related attitudes. Nordic Studies on Alcohol and Drugs 2016;33:361-80.

20. Dykema J, Stevenson J, Klein L, et al. Effects of E-Mailed Versus Mailed Invitations and Incentives on Response Rates, Data Quality, and Costs in a Web Survey of University Faculty. Soc Sci Comput Rev 2013;31:359-70.

21. Nilsen RM, Vollset SE, Gjessing HK, et al. Self-selection and bias in a large prospective pregnancy cohort in Norway. Paediatr Perinat Epidemiol 2009;23:597-608.

22. Garner DM, Olmsted MP. Scoring the eating disorder inventory. Am J Psychiatry 1986;143:680-a-680

23. Hughes ME, Waite LJ, Hawkley LC, et al. A short scale for measuring loneliness in large surveys: results from two population-based studies. Res Aging 2004;26:655-72.

24. Wittenberg M. Emotional and social loneliness: an examination of social skills, attributions, sex role, and object relations perspectives. Doctoral dissertation: University of Rochester, 1986.

25. Russell D, Cutrona CE, Rose J, et al. Social and emotional loneliness: an examination of Weiss's typology of loneliness. J Pers Soc Psychol 1984;46:1313-21.

26. Russell D, Peplau LA, Ferguson ML. Developing a measure of Ioneliness. J Pers Assess 1978;42:290-4.

27. Robinson JP, Shaver PR, Wrightsman LS. Measures of personality and social psychological attitudes. San Diego, CA: Academic Press, 1991.

28. Rosenvinge JH, Perry JA, Bjørgum L, et al. A new instrument measuring disturbed eating patterns in community populations: development and initial validation of a five-item scale (EDS-5). European Eating Disorders Review 2001;9:123-32.

29. Diener E, Emmons RA, Larsen RJ, et al. The satisfaction with life scale. J Pers Assess 1985;49:71-5.

30. Watson D, Clark LA, Tellegen A. Development and validation of brief measures of positive and negative affect: the PANAS scales. $J$ Pers Soc Psychol 1988;54:1063-70.

31. McManus S, Bebbington P, Jenkins R, et al. Mental health and wellbeing in England: adult psychiatric morbidity survey 2014. Leeds: NHS Digital, 2016. 
32. Madge N, Hewitt A, Hawton K, et al. Deliberate self-harm within an international community sample of young people: comparative findings from the Child \& Adolescent Self-harm in Europe (CASE) Study. J Child Psychol Psychiatry 2008;49:667-77.

33. American Psychiatric Association. Diagnostic and statistical manual of mental disorders. 5th ed. Arlington, VA: American Psychiatric Publishing, 2013

34. Olweus D. The Revised O/weus Bully/Victim Questionnaire. Bergen,Norway: Mimeo, Research Center for Health Promotion (HEMIL), University of Bergen, 1996.

35. Nansel TR, Overpeck M, Pilla RS, et al. Bullying behaviors among US youth: prevalence and association with psychosocial adjustment. JAMA 2001;285:2094-100.

36. American Association of University Women Educational Foundation. Hostile Hallway Survey on sexual harassment in America's schools.
Washington, DC: American Association of University Women Educational Foundation, 2001.

37. Gierk B, Kohlmann S, Kroenke K, et al. The somatic symptom scale-8 (SSS-8): a brief measure of somatic symptom burden. JAMA Intern Med 2014;174:399-407.

38. Saunders JB, Aasland OG, Babor TF, et al. Development of the Alcohol Use Disorders Identification Test (AUDIT): WHO Collaborative Project on Early Detection of Persons with Harmful Alcohol Consumption--II. Addiction 1993;88:791-804.

39. Kurtze N, Rangul V, Hustvedt BE, et al. Reliability and validity of selfreported physical activity in the Nord-Trøndelag Health Study (HUNT 2). Eur J Epidemiol 2007:22:379-87.

40. Hysing M, Pallesen S, Stormark KM, et al. Sleep and use of electronic devices in adolescence: results from a large populationbased study. BMJ Open 2015;5:e006748. 